\title{
Monitoring ERC Course Quality \& Faculty Performance Using Pareto's Principle
}

Nasr AO*, EIKhazin SE*, Mostafa MT*

\section{Rational:}

- Identifying and targeting substandard performance depend on the ability to detect any alarming patterns of course conduction.

\section{Purpose:}

- To generate a monitoring process of all ERC course activities and interventions performed under the umbrella of the Sudan-RC.

\section{Materials and Methods:}

- Prospective analysis of all ERC-ALS courses performed under Sudan-RC during 2018.

- An end-of-course standardized online feedback form of all activities and faculty performance is sent to candidates and faculty.

- Three domains were covered;

\section{Administration - Teaching Quality \\ Faculty Performance}

- Feedback contained 51 structured (5-points) Likert scale questions.

- Percentages and frequencies of Likert scale numerical grades were used to identify substandard performance.

- Substandard performance was defined as any score percentage $<80 \%$.

- Cronbach alpha was used to assess reliability.

- T-test to compare between different venues, directors or faculty members.

- A 20/80 Pareto's principle is then applied to target substandard items.

\section{Results:}

- Twenty-four ERC-ALS courses conducted during 2018.

- Five CDs, >20 faculty members and 315 candidates participated in these courses.

- Candidates' and faculty response rates were $21.6 \%$ and $63.2 \%$ respectively.

- Whole feedback Cronbach's alpha was 0.86 reflecting good reliability with error variance of 0.26 indicating good internal consistency.

- Only course administration was substandard $(87 \%)$ with good teaching and performance standard $>90 \%$.

- Manuals received < 2 weeks and program received $<1$ week were the main reasons for substandard administration.

- Pareto's chart was applied for different CDs, venues or faculty members using SPSS revealed no substandard patterns to be targeted operating 20/80 Pareto's principle .

- See e.g. lecture +/- demos for one CD referred to as CD-1 in the chart below.

\section{Conclusion:}

- Utilizing Pareto's principle can be used identify substandard performance patters.

- Pattern identification and correction could provide an effective monitoring process that specifically identify and target substandard items in course activities for correction.

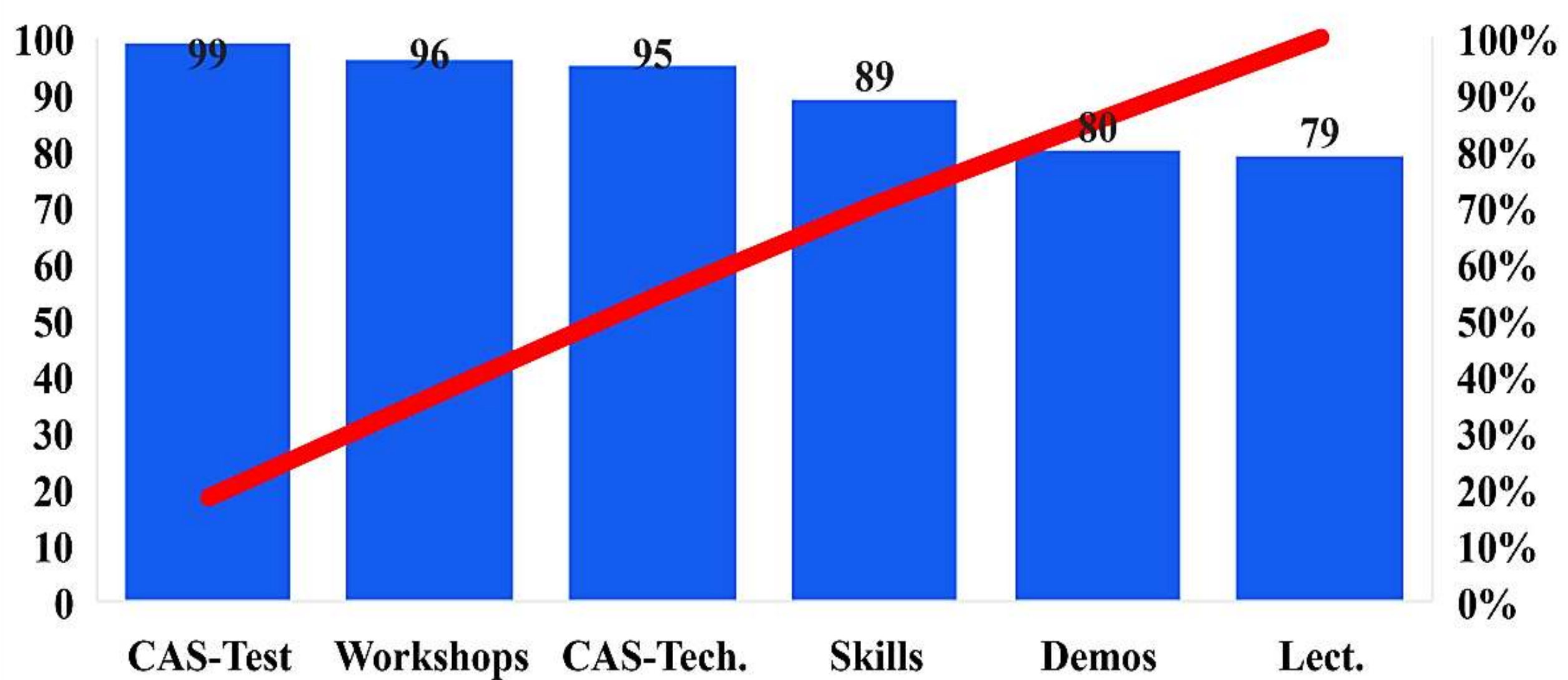

